\title{
Geological characteristics of shale in the Silurian (Sichuan) basin and chemical reaction of its reservoir under the action of fracturing fluid
}

\author{
Jun $\mathrm{Xu}^{1} \cdot$ Qianrui Huang ${ }^{1}$
}

Received: 19 January 2020 / Accepted: 25 March 2020 / Published online: 3 April 2020

(c) The Author(s) 2020

\begin{abstract}
The exploitation and exploration of shale gas is of great values to solve the energy problem. Taking the shale from Silurian Longmaxi formation in Sichuan Basin as an example, its geological characteristics and reservoir chemical reaction under the action of fracturing fluid were analyzed, and moreover, a series of data determination and fracturing fluid chemical reaction experiments were carried out. The results showed that the average total organic carbon value of shale in the study area was $4.79 \%$, the kerogen type was type I, the ratio of aliphatic structure to aromatic structure was smaller than 1 , the average $R_{\mathrm{O}}$ value was $2.15 \%$, the content of clay mineral in the mineral composition was high, the average porosity was $3.16 \%$, and the average permeability was $0.036 \times 10^{3} \mu \mathrm{m}^{2}$, which was conducive to shale gas generation; under the action of fracturing fluid, the sulfate mineral in the shale dissolved, clay mineral expanded, and the pore volume and specific surface area reduced. The results verify that the research area has shale gas mining value, and this study makes some contributions to further study the optimization of fracturing fluid and improve exploitation technology.
\end{abstract}

Keywords Shale $\cdot$ Fracturing fluid $\cdot$ Sichuan basin $\cdot$ China

\section{Introduction}

With the development of economy, the problem of energy shortage has become more important, and the demand for energy is increasing; hence, the development of new energy has attracted more and more attentions, for example, oil-gas exploration (Al-Fatlawi et al. 2017a, b). The world natural gas market is developing rapidly, and its proportion in the world energy is expected to increase to $27 \%$ in 2020 (Dmitrievsky 2005). However, most oil and gas reservoirs are rapidly consuming (Al-Fatlawi et al. 2017a, b), and natural gas is a non-renewable resource (Martin-Gil et al. 2019). Shale gas, a kind of methane based, very important clean energy, is a potential energy which develops in a sustainable way (Shar et al. 2018) and has long development life and rich resources, which is an ideal substitute for natural gas. It is found that

Qianrui Huang

vp5qrs@126.com

1 Environmental Geology Department, Yunnan Land and Resources Vocational College, Kunming 650106, Yunnan, China
China is rich in shale gas resources, and there are shale gas accumulation conditions in Junggar Basin (Pang et al. 2018), Ordos Basin (Zhao et al. 2016), Sichuan Basin (Zhang et al. 2015), etc., which has a very broad development prospect. Lin et al. (2016) analyzed the shale of Qiongzhusi, Wufeng and Longmaxi formation of Lower Paleozoic in the south of Sichuan and the north of Yunnan and found that their average quartz content was more than $27 \%$ and the relative brittleness index was also very high, i.e., they had good fracturing property. In the process of shale gas exploitation, due to the low permeability of the reservoir, it is necessary to form artificial fractures through large-scale fracturing (Maity 2015; Kahrilas et al. 2016) to obtain industrial gas flow. Various fracturing technologies have been studied extensively (Al-Fatlawi et al. 2019; Dai et al. 2019), but the fracturing fluid used in the production will often remain in the reservoir (Zhang et al. 2017), affecting the fracturing effect. Eveline et al. (2016) pointed out that the clay expansion pressure increased after the fracturing fluid intruded into the matrix under the permeability, resulting in the decrease in shale permeability and the formation of failure areas. Luek et al. (2018) found that there were a large number of halogenated organic molecular particles in the backflow fluid of fracturing fluid and 
the iodine ion in the backflow fluid continued to increase with the extension of time. This study analyzed the shale in Sichuan Basin from aspects of shale geological characteristics and the chemical reaction between fracturing fluid and reservoir. The geological characteristics of the shale in the research area were studied through X-ray diffractometer, and the chemical reactions between the shale and fracturing fluid were studied to obtain some information such as the organic geochemical characteristics and mineral composition of the shale. The changes of mineral composition and pore characteristics under the action of fracturing fluid were observed. This study aims to provide some theoretical supports for reasonable exploitation of shale gas and further improvement of exploitation level.

\section{Overview of the study area}

The limestone of Paleozoic and pre-Paleozoic is widely distributed in Sichuan Basin, and there is a large area of Mesozoic purplish red sandstone and mudstone and six sets of mature regional organic rich shale (Dong et al. 2015). The main research area of this study was Longmaxi formation of Lower Silurian system, whose main lithology was shale mixed with sandstone and limestone. The shale in that area was well exposed, which could be cored in large scale. The geographical location and lithologic profile of the study area is shown in Fig. 1.

\section{Experimental method}

\section{Geological characteristics survey}

Sichuan Basin is a part of the Yangtze platform. In the late Permian, magma erupted in the western part of the basin, forming a basalt eruption area (Long et al. 2011). In the late

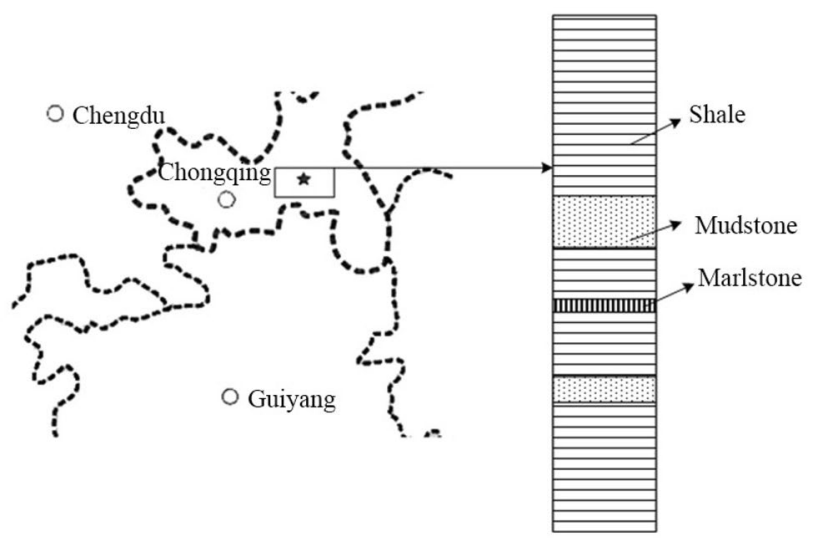

Fig. 1 Location and lithology profile of the study area
Triassic, the Indosinian movement (Singsoupho et al. 2014) uplifted the edge of the basin into mountains, ending the history of sea immersion. According to Wang et al. 2017, the Yanshan tectonic movements lead to the uplifting of the basin and major faults have been developed, associated by the modifications of the depositional facies from marine to transitional and then to continental facies, which is characterized by the predomination of mudstone, shale and sandstone. After the Himalayan orogeny (Qin et al. 2016), folding inversion occurred in the basin, forming a fault system.

Sichuan Basin is the largest outflow basin in China, which can be clearly divided into marginal mountains and basin bottom. The marginal mountains are mostly medium and low mountains, and the basin bottom is mostly hills, low mountains and plains. The terrain is high in the north and low in the south. It has three characteristics: plain landform in the west, hills landform in the middle and mountain landform in the east. It is bounded by Longquan Mountain and Huaying Mountain, with limestone widely exposed on the surface, followed by slate, schist, etc., and with granite and basalt locally. It is the most concentrated area of Mesozoic continental red beds in China. Longmaxi formation in Sichuan Basin is generally $10-170 \mathrm{~m}$ thick (Chen et al. 2014), with an average porosity of $4.71 \%$ (Chen et al. 2013), mature organic matter (Cao et al. 2016) and large amount of hydrocarbon generation, which is conducive to shale gas reservoir generation, and it is one of the favorable strata for shale gas exploration and development in China (Huang et al. 2012).

The survey content of geographical characteristics of the research area is as follows. Organic carbon was tested using Leco carbon and sulfur analyzer in accordance with GB/T 19145-2003. Vitrinite reflectance $\left(R_{\mathrm{O}}\right)$ was tested by microphotometer MPV-SP. X-ray diffraction (XRD) was analyzed using D8 DISCOVER X-ray diffractometer. Porosity and pulse permeability were measured using PDP200 pulse permeability meter. Magnetic resonance was analyzed using RecCore-04 low field nuclear magnetic resonance rock sample analyzer.

\section{Chemical reaction experiment}

Under the long-term infiltration of fracturing fluid, chemical reaction will occur in shale, which can change the mineral and pore structure of shale and affect the exploitation of shale gas. Six samples (Fig. 2) were taken from the study area, and samples which came from the same layer and were adjacent to the six samples were taken for comparative analysis. The sample surface was cleaned using distilled water and then they were put into the oven for drying. The formula of the fracturing fluid used in the experiment was $0.2 \%$ domestic resistance reducer (for reducing pressure loss), $0.15 \%$ cleanup additive, $0.05 \%$ demulsifier and $1 \%$ antiswelling agent (for preventing swelling and migration

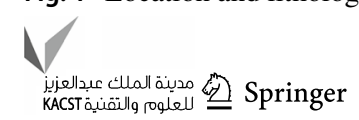




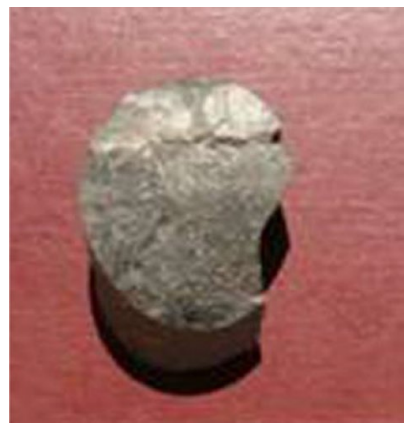

Fig. 2 The sample of core

Table 1 The chemical components of fracturing fluid

\begin{tabular}{lc}
\hline $\begin{array}{l}\text { Chemical compo-- } \\
\text { nents }\end{array}$ & $\begin{array}{c}\text { Concentra- } \\
\text { tion/(mg/L) }\end{array}$ \\
\hline $\mathrm{Al}^{3+}$ & 8.6 \\
$\mathrm{Ba}^{2+}$ & 0.4 \\
$\mathrm{Ca}^{2+}$ & 71.6 \\
$\mathrm{Cd}^{2+}$ & 2.8 \\
$\mathrm{Cl}^{-}$ & 426.4 \\
$\mathrm{Fe}^{2+}$ & 12.7 \\
$\mathrm{~K}^{+}$ & 14.2 \\
$\mathrm{Mg}^{2+}$ & 15.9 \\
$\mathrm{Mn}^{2+}$ & 0.2 \\
$\mathrm{NO}_{3}^{-}$ & 30.3 \\
$\mathrm{Na}^{+}$ & 78.2 \\
$\mathrm{~Pb}^{2+}$ & 0.07 \\
$\mathrm{SO}_{4}^{2-}$ & 58.2 \\
\hline
\end{tabular}

of clay minerals), and its chemical components are shown in Table 1.

The experiment was performed in a high temperature and pressure stainless batch tank reactor which has polytetrafluoroethylene equipment liner. There was $90 \mathrm{~mL}$ of solvent, and it could bear a maximum pressure of $40 \mathrm{MPa}$. The experimental facility is shown in Fig. 3. The sample was put at the bottom of the reactor. Then, $40 \mathrm{~mL}$ of fracturing fluid was taken by a pipette and added to the reactor. The reaction temperature was $90^{\circ} \mathrm{C}$. The pressure in the reactor was controlled through constant flow pump. The reaction period was $24 \mathrm{~h}, 48 \mathrm{~h}$ and $72 \mathrm{~h}$. The sample and solution were taken out at the end of the experiment.

\section{Research results}

\section{Geological characteristics of shale}

\section{Organic geochemical characteristics}

The higher the content of total organic carbon (TOC), the greater the adsorption capacity of shale gas. It was found that the content of TOC of shale in the study area was relatively high (Table 2), between 1.06 and $6.64 \%$, and the average content of TOC was $4.79 \%$. Kerogen can be divided into type I, type II and type III according to the elemental composition. It was found through analysis that kerogen in the study area was type I, which was more likely to produce hydrocarbon gas; the ratio of aliphatic structure to aromatic structure in kerogen was smaller than 1, indicating strong humic feature, and the $R_{\mathrm{O}}$ value was between 1.51 and $2.87 \%$ (average $2.15 \%$ ), which was conducive to the formation of shale gas.

\section{Mineral composition of reservoir}

The results of XRD analysis on 100 samples from Longmaxi formation are shown in Table 3. It is seen from Table 3 that the mineral composition of different samples was different; some samples were mainly composed of clay minerals (e.g., X-2 and X-98), some samples were mainly composed of quartz (e.g., X-10), and some samples were mainly composed of carbonate minerals (e.g.,

Fig. 3 The experimental facility

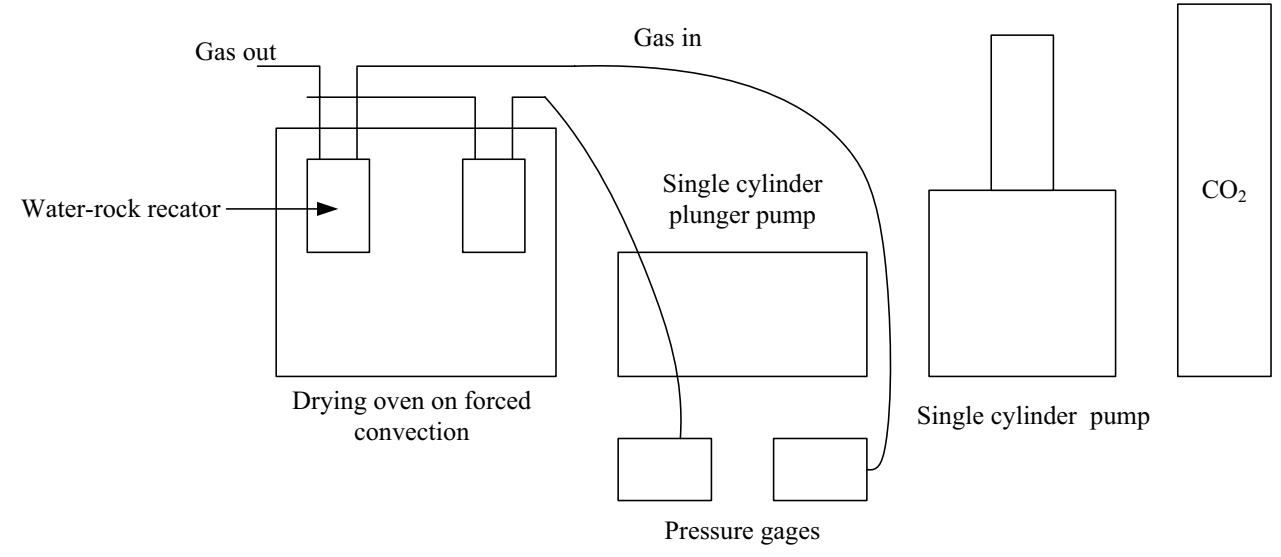


Table 2 Organic geochemical parameters of samples

\begin{tabular}{lllll}
\hline Sample number & TOC content/\% & $\begin{array}{l}\text { Kerogen } \\
\text { type }\end{array}$ & $\begin{array}{l}\text { Ratio of aliphatic structure to aro- } \\
\text { matic structure of kerogen }\end{array}$ & $R_{\mathrm{O}} / \%$ \\
\hline Y-1 & 6.52 & I & 0.51 & 1.75 \\
Y-2 & 1.36 & I & 0.64 & 2.12 \\
Y-3 & 5.48 & I & 0.53 & 1.51 \\
Y-4 & 4.36 & I & 0.72 & 1.67 \\
Y-5 & 6.62 & I & 0.89 & 1.78 \\
Y-6 & 6.36 & I & 0.76 & 2.45 \\
Y-7 & I & 0.84 & 2.36 \\
Y-8 & 6.64 & I & 0.56 & 2.58 \\
Y-9 & 5.18 & I & 0.74 & 2.87 \\
Y-10 & 6.49 & I & 0.64 & 2.67 \\
Y-11 & 2.36 & I & 0.56 & 2.32 \\
Y-12 & 4.52 & I & 0.62 & 2.15 \\
Y-13 & 4.56 & I & 0.76 & 2.22 \\
Y-14 & 5.49 & I & 0.71 & 1.78 \\
Y-15 & 6.56 & I & 0.59 & 1.68 \\
Y-16 & 3.68 & I & 0.97 & 1.57 \\
Y-17 & 2.68 & I & 0.84 & 2.07 \\
Y-18 & 3.68 & I & 0.55 & 2.17 \\
Y-19 & 5.69 & I & 0.49 & 2.55 \\
Y-20 & 6.56 & I & 0.68 & 2.63 \\
\hline & 1.06 & & &
\end{tabular}

Table 3 The mineral composition of samples

\begin{tabular}{llll}
\hline Sample number & $\begin{array}{l}\text { Clay mineral } \\
\text { content/\% }\end{array}$ & $\begin{array}{l}\text { Quartz con- } \\
\text { tent/\% }\end{array}$ & $\begin{array}{l}\text { Carbonate } \\
\text { mineral con- } \\
\text { tent/\% }\end{array}$ \\
\hline X-1 & 6.8 & 26.7 & 66.5 \\
X-2 & 86.3 & 1.3 & 12.4 \\
X-3 & 71.2 & 5.6 & 23.2 \\
X-4 & 17.2 & 8.9 & 73.9 \\
X-5 & 56.3 & 11.5 & 32.2 \\
X-6 & 37.6 & 54.3 & 8.1 \\
X-7 & 48.3 & 31.2 & 20.5 \\
X-8 & 36.7 & 27.8 & 35.5 \\
X-9 & 75.1 & 12.6 & 12.3 \\
X-10 & 12.5 & 64.8 & 22.7 \\
X-11 & 56.8 & 14.6 & 28.6 \\
X-12 & 64.7 & 6.9 & 28.4 \\
X-13 & 36.8 & 42.8 & 20.4 \\
$\ldots$ & $\ldots$ & $\ldots$ & $\ldots$ \\
X-95 & 71.5 & 2.6 & 25.9 \\
X-96 & 42.6 & 7.9 & 49.5 \\
X-97 & 51.2 & 25.6 & 23.2 \\
X-98 & 89.6 & 5.6 & 4.8 \\
X-99 & 11.5 & 45.8 & 42.7 \\
X-100 & 21.9 & 24.7 & 53.4 \\
\hline & & &
\end{tabular}

$\mathrm{X}-1$ and $\mathrm{X}-4)$; overall, the content of clay mineral in the shale was relatively high, between 6.7 and $91.2 \%$, with an average value of $49.6 \%$, the content of quartz was between 0.3 and $72.6 \%$, with an average value of $23.6 \%$, and the content of carbonate mineral was between 0.2 and $81.7 \%$, with an average value of $14.2 \%$.

\section{Pore characteristics}

Original information obtained by nuclear magnetic resonance method cannot be directly used, and useful information can only be obtained by $\mathrm{T}_{2}$ spectrum through inversion. $\mathrm{T}_{2}$ distribution map can reflect parameters of reservoir such as porosity and permeability, providing important information for reservoir evaluation. Four samples were taken as examples, and their $\mathrm{T}_{2}$ distribution maps are shown in Fig. 4. It is seen from Fig. 4 that $T_{2}$ spectra showed bimodal distribution, and the second peak was at $10 \mathrm{~ms}$, indicating that there were some large pores in the reservoir besides small pores; after centrifugation, $\mathrm{T}_{2}$ spectra showed unimodal distribution, indicating that the pores were mostly small pores with few movable fluid. The porosity of the samples was between 1 and 5\% (Table 4) (average $3.16 \%$ ), the permeability was between $0.001 \times 10^{3}$ and $0.100 \times 10^{3} \mu \mathrm{m}^{2}$ (average $0.036 \times 10^{3} \mu \mathrm{m}^{2}$ ), showing good reservoir forming conditions. 
Fig. $4 \mathrm{~T}_{2}$ distribution diagrams of samples

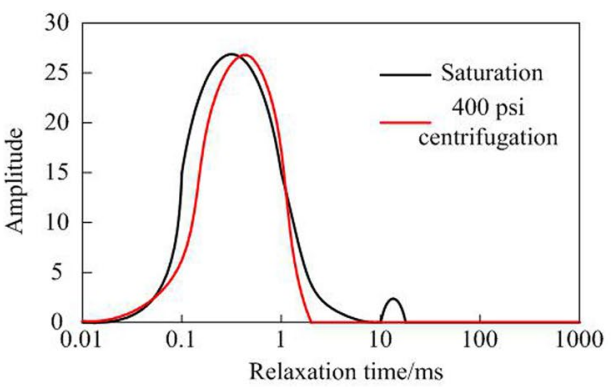

(1)

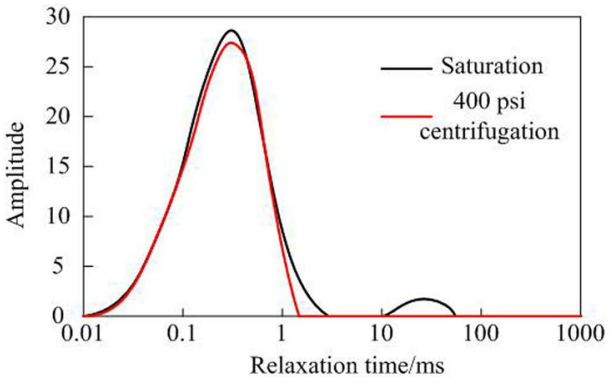

(3)

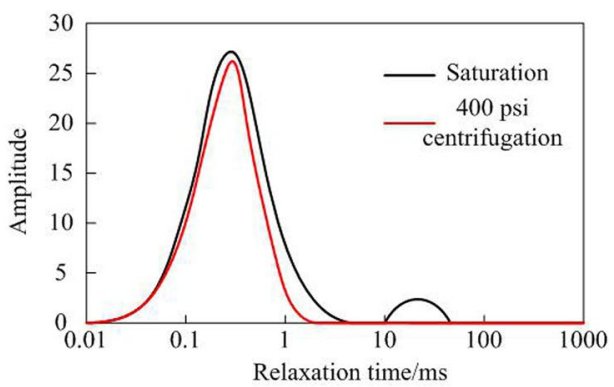

(2)

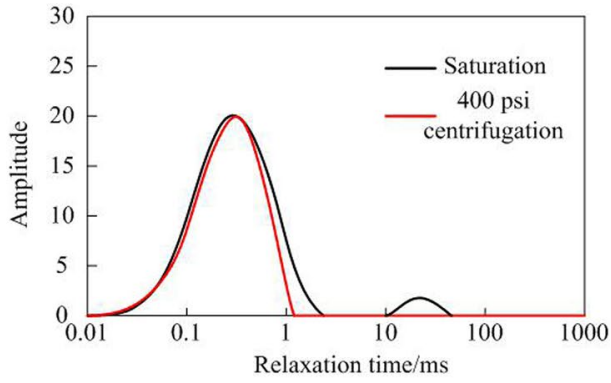

(4)
Table 4 The porosity distribution of samples

\begin{tabular}{lllll}
\hline & $1-2 \%$ & $2-3 \%$ & $3-4 \%$ & $4-5 \%$ \\
\hline Number of samples $/ n$ & 37 & 18 & 28 & 17 \\
\hline
\end{tabular}

\section{Chemical reaction results of shale and fracturing fluid}

The comparison of the mineral composition of the original shale and the shale after the reaction with the fracturing fluid is shown in Table 5. It was found that the content of calcite and dolomite in the shale decreased significantly after the reaction with the fracturing fluid, and the changes of the other components were small.

Due to the dissolution of sulfate minerals, i.e., calcite and dolomite, in the shale, the $\mathrm{pH}$ value of the drainage solution changed. The $\mathrm{pH}$ value of the discharged fluid in different time periods was determined. The $\mathrm{pH}$ value of the original fracturing fluid was 4.7, i.e., the fluid was acid. The $\mathrm{pH}$ value of the discharged fluid was 6.5 after $24 \mathrm{~h}$ and 6.7 after $48 \mathrm{~h}$, i.e., the fluid was neutral. After $72 \mathrm{~h}$, it was 6.4.

In the fracturing fluid, a large amount of $\mathrm{H}^{+}$was released from the resistance reducer by hydrolysis, which reacted with sulfate minerals. The process is as follows:

$\mathrm{CaCO}_{3}+2 \mathrm{H}^{+}=\mathrm{Ca}^{2+}+\mathrm{CO}_{2}+\mathrm{H}_{2} \mathrm{O}$

$\mathrm{CaMg}\left(\mathrm{CO}_{3}\right)_{2}+4 \mathrm{H}^{+}=\mathrm{Ca}^{2+}+\mathrm{Mg}^{2+}+2 \mathrm{CO}_{2}+2 \mathrm{H}_{2} \mathrm{O}$

In addition to the change of mineral composition, the pore characteristics of the shale changed under the influence of the fracturing fluid. As shown in Table 6, after chemical reaction, the pore volume and specific surface area of the shale decreased significantly, and the reason for such a phenomenon was that clay minerals expanded after reacting with the fracturing fluid, blocking the original pores in the shale.
Table 5 Changes of shale mineral composition (A represents the original shale, $\mathrm{A}^{*}$ represents the shale after reaction with fracturing fluid, the same below)

\begin{tabular}{|c|c|c|c|c|c|c|c|c|}
\hline \multirow{2}{*}{$\begin{array}{l}\text { Sample } \\
\text { number }\end{array}$} & \multicolumn{3}{|c|}{ Clay minerals/\% } & \multicolumn{5}{|c|}{ Minerals/\% } \\
\hline & $\begin{array}{l}\text { Total } \\
\text { content of } \\
\text { clay }\end{array}$ & $\begin{array}{l}\text { Illite/smectite } \\
\text { formation }\end{array}$ & Chlorite & Quartz & Calcite & Dolomite & Pyrite & Plagioclase \\
\hline A & 15 & 97 & 3 & 36 & 35 & 8 & 3 & 3 \\
\hline $\mathrm{A}^{*}$ & 18 & 96 & 4 & 37 & 31 & 6 & 3 & 5 \\
\hline B & 16 & 96 & 4 & 36 & 36 & 7 & 2 & 3 \\
\hline $\mathrm{B}^{*}$ & 19 & 95 & 5 & 37 & 32 & 5 & 2 & 5 \\
\hline $\mathrm{C}$ & 16 & 97 & 3 & 35 & 35 & 7 & 3 & 4 \\
\hline $\mathrm{C}^{*}$ & 19 & 95 & 5 & 36 & 31 & 5 & 3 & 6 \\
\hline
\end{tabular}


Table 6 Pore characteristics of shale

\begin{tabular}{llc}
\hline Sample number & Pore volume $\left(\mathrm{cm}^{3} / \mathrm{g}\right)$ & $\begin{array}{l}\text { Specific } \\
\text { surface area } \\
\left(\mathrm{m}^{3} / \mathrm{g}\right)\end{array}$ \\
\hline A & 0.01346 & 13.54 \\
A $^{*}$ & 0.00864 & 8.24 \\
B & 0.01354 & 12.78 \\
B $^{*}$ & 0.00798 & 8.64 \\
C & 0.01365 & 13.62 \\
C $^{*}$ & 0.00852 & 8.53 \\
\hline
\end{tabular}

\section{Discussion}

Sichuan Basin is an important natural gas production area in China and a shale gas exploration test base. It has formed a good industrial production capacity and initially formed a mining and management technology in line with the geological characteristics of shale gas in the basin, with excellent drilling and fracturing reformation technologies. It has established orderly mining plans, standardized the production process, and made a great contribution to the local economic development.

This paper mainly analyzed the shale of Longmaxi formation, including the analysis of geological characteristics and chemical reaction of shale reservoir. The analysis results of geological characteristics of the shale demonstrated that the TOC content in the study area was relatively high, the main kerogen was type I, the maturity of organic matter was also relatively good, most of which were clay minerals, and the development of pores was good, providing a good condition for shale gas generation. In addition, the gentle terrain and absence of large-scale fault zones provide good preservation conditions, which is very helpful for shale gas development and exploration. The chemical reaction between shale reservoir and fracturing fluid showed that the retention of fracturing fluid in shale changed the mineral composition. In the process of reaction, water molecule entered minerals along the crack to form water molecule layer to absorb water, leading to uneven expansion, disintegration and dispersion. The dissolution of sulfate minerals reduced the porosity, which was not conductive to exploitation. In the mineral composition of shale, illite and montmorillonite expanded by absorbing water, destroying the pores and leading to reduced pore volume and specific surface area and dolomite and calcite dissolved, destroying the reservoir structure, which had a great influence on shale gas exploitation. Therefore, in the process of fracturing, the composition of chemical components of the fracturing fluid should be paid attention to improve the efficiency of fracturing mining. At present, in shale gas exploitation in China and abroad, the flowback rate of fracturing fluid is relatively low (Yan et al. 2015), and about
$10-30 \%$ fracturing fluid returns to the ground (Tikhomirova et al. 2011). In addition to affecting the shale gas exploitation effect, the remaining fracturing fluid may also contain a large number of salts $(\mathrm{Cl}, \mathrm{Br})$ which will promote the dissolution of carbonate minerals (Joewong et al. 2015) and metal pollutant (Countess et al. 2014) and heavy metal pollutant (Dustin et al. 2018) which will change the permeability of rock (Harrison et al. 2017). Fletcher (2012) pointed out that the overflow of fracturing fluid brought large pollution risk to the underground water resource of Pennsylvania. Therefore, fracturing chemical products have begun the transition to being the least harmful to the environment and human health (Hurley et al. 2016). Further improvement of fracturing technology is the key point in shale gas production (Huang 2019).

Great achievements have been made in shale gas development in Sichuan Basin, but there are still some challenges. For example, in addition to the developed mature shale gas areas, the distribution of shale gas in other areas of Sichuan Basin is not clear, and there are still some technical restrictions on the development of deep shale gas resources. But in general, Sichuan Basin is rich in shale gas resources, showing a good development prospect, and the large-scale exploration and mining can be carried out in Sichuan Basin, but the flowback of fracturing fluid should be paid attention to.

\section{Conclusion}

Taking the shale of Longmaxi formation as an example, this paper analyzed its geological characteristics and chemical reactions. It was found that:

1. The TOC content of the shale in the study area was between 1.06 and $6.64 \%$, the kerogen type was type I, and $\mathrm{R}_{\mathrm{O}}$ value was between 1.51 and $2.87 \%$, which was conducive to shale gas enrichment;

2. The shale in the study area had high clay mineral content and strong adsorption capacity for gas;

3. The shale porosity was between 1 and $5 \%$, and the per-

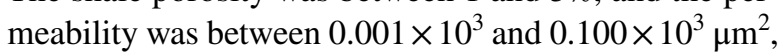
which provided good reservoir forming conditions;

4. When the shale reacted with the fracturing fluid, sulfate minerals dissolved and pore volume and specific surface area decreased.

\section{Compliance with ethical standards}

Conflict of interest The authors declare that they have no conflict of interest.

Open Access This article is licensed under a Creative Commons Attribution 4.0 International License, which permits use, sharing, adaptation, distribution and reproduction in any medium or format, as long 
as you give appropriate credit to the original author(s) and the source, provide a link to the Creative Commons licence, and indicate if changes were made. The images or other third party material in this article are included in the article's Creative Commons licence, unless indicated otherwise in a credit line to the material. If material is not included in the article's Creative Commons licence and your intended use is not permitted by statutory regulation or exceeds the permitted use, you will need to obtain permission directly from the copyright holder. To view a copy of this licence, visit http://creativecommons.org/licenses/by/4.0/.

\section{References}

Al-Fatlawi O, Hossain MM, Osborne J (2017a) Determination of best possible correlation for gas compressibility factor to accurately predict the initial gas reserves in gas-hydrocarbon reservoirs. Int J Hydrog Energy 42(40):25492-25508

Al-Fatlawi O, Roy V, Aswin R, Hossain MM, Kabir AH. (2017b) Optimization of infill drilling in Whicher range field in Australia. In: SPE Kingdom of Saudi Arabia annual technical symposium and exhibition. Society of Petroleum Engineers

Al-Fatlawi O, Hossain M, Patel N, Kabir A (2019) Evaluation of the potentials for adapting the multistage hydraulic fracturing technology in tight carbonate reservoir. In: SPE middle east oil and gas show and conference. Society of Petroleum Engineers

Cao C, Lv Z, Li L, Du L (2016) Geochemical characteristics and implications of shale gas from the Longmaxi Formation, Sichuan Basin, China. J Nat Gas Geosci 1(2):131-138

Chen SB, Xia XG, Qin Y, Fu CQ, Hu L (2013) Classification of pore structures in shale gas reservoir at the Longmaxi Formation in the south of Sichuan Basin. J China Coal Soc 38(5):760-765

Chen S, Zhu Y, Qin Y, Wang H, Liu H, Fang J (2014) Reservoir evaluation of the Lower Silurian Longmaxi Formation shale gas in the southern Sichuan Basin of China. Mar Petrol Geol 57:619-630

Countess S, Boardman G, Hammack R, Hakala A (2014) Evaluating leachability of residual solids from hydraulic fracturing in the marcellus shale. Proc Water Environ Fed 19:1581-1592

Dai C, Liu H, Wang Y, Li X, Wang W (2019) A simulation approach for shale gas development in China with embedded discrete fracture modeling. Mar Petrol Geol 100:519-529

Dmitrievsky A. (2005) Meeting natural gas demand: global and regional challenges. In: 18th World Petroleum Congress

Dong D, Gao S, Huang J, Guan Q, Wang S, Wang Y (2015) A discussion on the shale gas exploration and development prospect in the Sichuan Basin. Nat Gas Ind 31:1-15

Dustin MK, Bargar JR, Jew AD, Harrison A, Joe-Wong C, Thomas D, Brown GE Jr, Maher K (2018) Shale kerogen-hydraulic fracturing fluid interactions and contaminant release. Energy Fuels 32(9):8966-8977

Eveline VF, Akkutlu IY, Moridis GJ (2016) Numerical simulation of hydraulic fracturing water effects on shale gas permeability alteration. Transp Porous Med 116:1-26

Fletcher SM (2012) Risk assessment of groundwater contamination from hydraulic fracturing fluid spills in Pennsylvania. 26(5):494-498

Harrison AL, Jew AD, Dustin MK, Thomas DL, Joe-Wong GM, Bargar JR, Johnson N, Brown GE, Maher K (2017) Element release and reaction-induced porosity alteration during shale-hydraulic fracturing fluid interactions. Appl Geochem 82:47-62

Huang C (2019) Fracability evaluation of shale of the Wufeng-Longmaxi formation in the Changning Area, Sichuan Basin. Acta Geol Sin (English edition) 93:996-1004

Huang JL, Ju CN, Li JZ, Dong DZ, Wang SJ, Wang SQ, Wang YM, Li DH (2012) Shale gas accumulation conditions and favorable zones of Silurian Longmaxi Formation in south Sichuan Basin, China. J China Coal Soc 37(5):782-787

Hurley T, Chhipi-Shrestha G, Gheisi A, Hewage KN, Sadiq R (2016) Characterizing hydraulic fracturing fluidgreenness: application of a hazard-based index approach. Clean Technol Environ 18(3):647-668

Joewong CM, Harrison AL, Thomas D, Dustin MK, Jew AD, Brown GE, Maher K, Bargar J (2015) Coupled mineral dissolution and precipitation reactions in shale-hydraulic fracturing fluid systems. Agu Fall Meeting. AGU Fall Meeting Abstracts

Kahrilas GA, Blotevogel J, Corrin ER, Borch T (2016) Downhole transformation of the hydraulic fracturing fluid biocide glutaraldehyde: implications for flowback and produced water quality. Environ Sci Technol 50:11414-11423

Lin D, Zhang TS, Liao JJ, Liao MG, Geng D, Ren XC, Chen YL (2016) Mineral composition and brittleness analysis of organic-rich lower Paleozoic shale in South Sichuan and North Yunnan Areas of China. Chem Technol Fuels Oil 52:218-223

Long S, Wu S, Li H, Bai Z, Ma J, Zhang H (2011) Hybrid sedimentation in late permian-early triassic in western Sichuan basin. China. J Earth Sci 22(3):340-350

Luek JL, Harir M, Schmitt-Kopplin P, Mouser PJ, Gonsior M (2018) Temporal dynamics of halogenated organic compounds in Marcellus Shale flowback. Water Res 136:200-206

Maity D (2015) Correlating pressure with microseismic to understand fluid-reservoir interactions during hydraulic fracturing. J Sust Energy Eng 3:127-142

Martin-Gil V, Ahmad MZ, Castro-Muñoz R, Fila V (2019) Economic framework of membrane technologies for natural gas applications. Sep Purif Rev 48(4):298-324

Pang H, Pang XQ, Dong L, Zhao X (2018) Factors impacting on oil retention in lacustrine shale: Permian Lucaogou Formation in Jimusaer Depression, Junggar Basin. J Petrol Sci Eng 163:79-90

Qin S, Zhou G, Li W, Hou Y, Lü F (2016) Geochemical evidence of water-soluble gas accumulation in the Weiyuan gas field, Sichuan Basin. Nat Gas Ind B 3(1):37-44

Shar AM, Mahesar AA, Memon KR (2018) Could shale gas meet energy deficit: its current status and future prospects. J Petrol Explor Prod Technol 8(4):957-967

Singsoupho S, Bhongsuwan T, Elming S (2014) Tectonic evaluation of the Indochina Block during Jurassic-Cretaceous from palaeomagnetic results of Mesozoic redbeds in central and southern Lao PDR. J Asian Earth Sci 92:18-35

Tikhomirova AV, Yagudina RI, Kulikov AU (2011) Characterization of microbial diversity in treated and untreated flowback water impoundments from gas fracturing operations. Ind Eng Chem Res 85(5):293-304

Wang Y, Wang H, Zhang C, Li X, Dong D (2017) Fracture pore evaluation of the Upper Ordovician Wufeng to Lower Silurian Longmaxi Formations in southern Sichuan Basin, SW China. Pet. Explor Dev 44(4):563-572

Yan Q, Lemanski C, Karpyn ZT, Ayala LF (2015) Experimental investigation of shale gas production impairment due to fracturing fluid migration during shut-in time. J Nat Gas Sci Eng 24:99-105

Zhang X, Shi W, Xu Q, Wang R, Xu Z, Wang J, Wang C, Yuan Q (2015) Reservoir characteristics and controlling factors of shale gas in Jiaoshiba area, Sichuan Basin. Acta Petrol Sin 36:926-939

Zhang T, Li XF, Wang YH, Shi JT, Yang LF, Sun Z, Yang J, Zhang XH (2017) Study on the effect of gas-shale reservoir special properties on the fracturing fluid recovery efficiency and production performance. Nat Gas Geosci 28:828-838

Zhao J, Wang R, Er C (2016) Adsorption characteristics of Chang 7 shale from the Triassic Yanchang Formation in Ordos Basin, and its controlling factor. Earth Sci Front 23:146-153

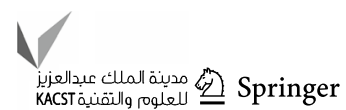


Publisher's Note Springer Nature remains neutral with regard to jurisdictional claims in published maps and institutional affiliations. 